\title{
Discussion on the Significance of Negative Planning in Small-town Landscape Design
}

\author{
Yijing Song \\ Huanghe Science and Technology College \\ Zhengzhou, Henan, 45000
}

\begin{abstract}
The significance of negative planning in small-town landscape design can be learned through the most common landscape problems found in small towns, mainly manifested in three aspects: 1. natural ecosystem service function; 2 . biological environment safety; 3 . human landscape preservation. For the natural ecosystem service function, it's analyzed mainly from four respects: the significance of landform service function, the significance of climate service function, the significance of soil service function and the significance of hydrology service function; For the biological environment safety, it's elaborated mainly from two respects: the significance of animal environment safety and the significance of plant environment safety; For the human landscape preservation, it's analyzed mainly from four respects: the significance of nature landscape preservation, the significance of religious culture landscape preservation, the significance of historical buildings, streets and sites preservation and the significance of vernacular culture landscape preservation.
\end{abstract}

Keywords—negative planning; small town; landscape design; Jinxiang Town

\section{INTRODUCTION}

Nowadays, the landscape design in China's small-town planning on the concrete forms is mainly displayed by: focus on the reasonable plane layout, mainly for floor planning which lacks the consideration on natural ecology, humanity history and sustainable development, absence of correspondency to small town design. On the one hand, the landscape of small towns is stereotyped and follows the same pattern due to the blind pursuit of big road, big square, big lawn and big city and the influence of the "European Style" and "Vintage Style" without connotation as well as the "Modern Style" which has not been out of fashion for decades. On the other hand, with an idea of seeking novelty, some small towns regard peculiarity as beauty, blindly mixing and matching, which they believe is "creative and unique", however, results in the "awkward" and "bizarre" forms (Fig. 1). Besides, for the planning procedure, paramount consideration has been given to the development needs while land health and safety is ignored. Furthermore, for the outcome, the changeable beautiful "image" is always pursued while the "bottom line" of safety pattern has been repeatedly violated. All these factors have deprived a small town of original appearance, locality and uniqueness, destroying its landscape and hindering its substantial development.
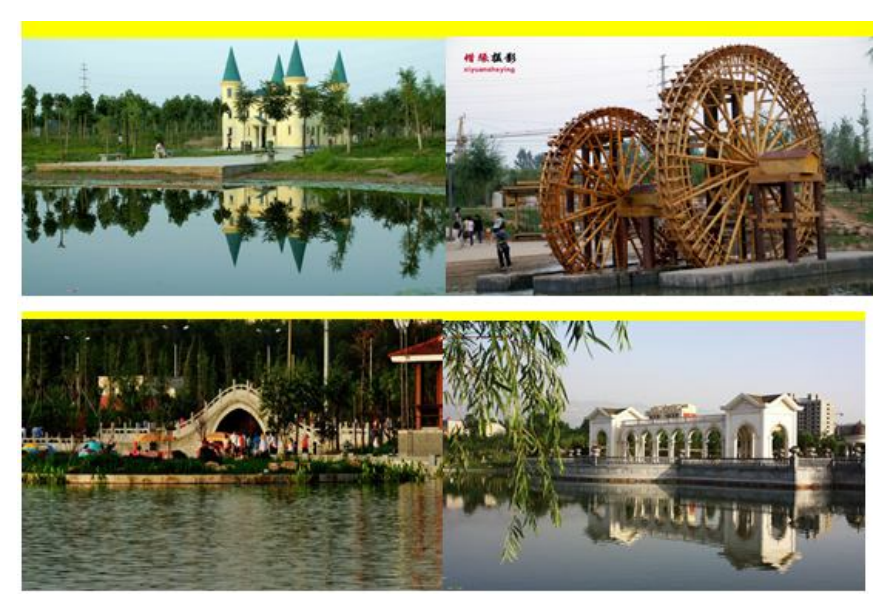

Fig. 1. Landscape of the People's Park in a small town

Based on the "negative planning" idea, the small-town landscape planning problem can be settled proceeding from three aspects: nature, biology and human. In this paper, the significance of "negative planning" in small-town landscape design has been detailedly elaborated from the following three aspects.

\section{ORGANIZATION OF THE TEXT}

\section{A. The significance of natural ecosystem service function}

Natural ecosystem refers to a relatively stable ecological system developing based on natural regulation capacity in certain time and space scope, such as original forest, sea, etc. ${ }^{[1]}$ While the ecosystem service function refers to the natural environment conditions and their effectiveness which the mankind depends on for living formed and maintained by ecological system and ecological process. ${ }^{[2]}$

How to use the "negative planning" approach to guide the settlement of problems relating to "natural ecosystem" in small-town landscape design? First, rethink the landscape state of small towns: the disrespect for nature has become a priority issue in today's small-town landscape state; "negative planning" first is a reflection on this state, emphasizing the central premise of landscape's respect for nature. Second, the "negative planning" idea stresses the reflection on the traditional planning method, while the method for small-town landscape planning in nowadays is that: guided by the thought to meet people's all needs, the safety problems of natural 
ecosystem have been totally ignored and some design even is against the law of nature. Third, the "negative planning" idea stresses the reversed planning procedure while today's smalltown landscape design has given priority to "profit" rather than "nature". At last, the "negative planning" idea stresses the "negative planning result", laying emphasis on the respect for nature and protection of ecological environment, first planning the "no construction area" and "no plot area", which is also contrary to the conventional focus on the appearance form presented in the planning.

\section{1) The significance of landform service function}

The landform which the mankind depends on for living has provided us a spatial place for our production and livelihood, which is the foundation for people to carry out all activities.

In the traditional landscape planning and design, little importance has been attached to the safety of natural landscape landform but more to the transformation of the current landform into the state desired by people. For instance, to speed up the development and process of modernization, urbanization and industrialization, plenty of small towns have conducted: land reclamation from marshes, river filling, lake filling; river channel sedimentation; construction for ground elevation, etc. These actions has led to the reduction of water area and the decrease of riverway natural flood discharge width, which diminishes the flood plain area and magnifies the threat of flood; meanwhile, the flood regulation capacity of river network has been impaired, which increases the pressure for flood control structural measures; in addition, the river has further become over ground river, which increases the risk of flood as well as the difficulty and workload of flood control.

Under guidance of the negative planning idea, there have been changes not only in the though of design but also in the fulfillment of planning method, planning procedure and planning result, which improves the existing issues and helps to establish the security pattern of landform, thereby solving the problems including: loss of productivity caused by water and soil erosion, decrease of rainwater utilization rate, reduction of water resources, decline of water quality, drop in generating capacity and increase of flood occurrence rate, and more importantly ensuring the safety of human living environment. The negative planning plays a vital role in reducing these losses as mentioned above, which is exactly the significance of landform service function.

\section{2) The significance of climate service function}

Climate is the general atmospheric state of an area in the world over many years and the comprehensive manifestation of various weather processes during this period. The major factors affecting climate include natural and human factors, of which the natural factors are irresistible but the human factors that lead to climate deterioration shall arouse people's reflection.

Climate changes have great impact on human beings and natural systems. Since the ecosystem and human society have adapted to today's and recently past climate, if the climate changes too fast to be adapted for the ecosystem and human society, it will be very difficult for people to cope with these changes. To meet the endless demands, human beings have been constantly exploring and largely using the energy, resulting in the unceasing occurrence of various hazards like the global warming, poor air quality, serious air pollution, frequent occurrence of extreme weather, etc. Typhoon, tsunami, earthquake and other natural disasters have brought immeasurable losses and damage to us while the reason for causing these is just the incorrect ways that human beings have used for the state, city and town landscape construction and planning. The "negative planning" idea is generated exactly to change the current situation and renew the global climate. Moreover, favorable weather conditions are able to increase the yield of crops, guarantee the basic necessities of life, enhance the life quality of human beings, improve our living environment, reduce the risk of catastrophe and increase the life span, all of which are exactly the significance of climate service function.

\section{3) The significance of soil service function}

As a crucial element of national wealth, soil is the source of basic necessities of life that the mankind depends on for living. However, in the process of modern urbanization, very little attention has been paid to its safety by landscape designers. In the landscape design, construction has been arbitrarily conducted without consideration on the bearing capacity of soil plants with beautiful appearance and visual effect have been cultivated without consideration on the soil $\mathrm{pH}$; complex network traffic with increasingly wide road and constantly compacted road surface has been wildly established without consideration on the soil vitality. The soil pollution and destruction has led to the decline in biological quality, economic losses, damage to human health, eco-environment system degradation, etc., which has extremely serious consequences for our existence. While the soil eco-service function mainly includes:

To provide a good place for plant growth and development;

To provide plants with nutrients;

To play a key role in the circulation of macronutrients like nitrogen, carbon, sulfur, etc.

The "negative planning" idea has emphasized that soil and other natural factors shall be regarded as one of the priority conditions in town landscape design.

Therefore, the soil eco-service function is of great importance to the mankind and the human living environment.

\section{4) The significance of hydrology service function}

Water is the foundation for existence of all things and an importance matter next only to oxygen. Up to 70 percent of the human body is water: thus it can be seen that water is the vitality.

The hydrology eco-service function includes: the source of human life, the source of plant life, the blood of industry, a vital role for climate, geography, life and ecological environment.

In the landscape design, there are four forms of water we all know: still water, flowing water, falling water and gushing water, which represent different forms of water bodies, such as: fountain, waterfall, river and lake. The four forms of water also constitute the water circulation system. The water will be alive only through the unceasing circulation and the fusion with 
living vegetation, soil and climate. In the traditional town landscape planning, there are many problems in the waterscape design, such as: no establishment of connection with surrounding water systems, blind pool digging and hill making, no bestowal of vitality to the water which is separated from soil and creatures by construction materials, no attention paid to the water circulation thereby leaving the water in a lifeless condition, no attention paid to the influence of industrial sewage and domestic waste on water thereby making the water system severely polluted, no treatment to the polluted water bodies thereby causing harm to the life health and survival environment of human beings and other creatures. While according to the "negative planning" idea, we shall give top priority to the security pattern of water bodies, first respecting the laws of nature, and the waterscape created in this way is the water landscape design in the truest sense of the word.

\section{B. The significance of biological environment safety}

\section{1) The significance of animal environment safety}

In the current landscape planning of small towns, many planning thoughts and design ideas have seriously affected the safety of the animals living environment. For example, in the design of the road traffic of the landscape planning of small towns, growing transport network and more and more wide roads, bring potential safety hazard to the communication and migration of animals, thus animals are often caused to die because of car accidents when crossing the road; in the aspect of water resources, the surrounding planning of drainage is not reasonable either in planning industrial area of the upstream of river system, or in the both banks of the water for chaotic development, causing pollution to water, and giving rise to harm the amount and type of aquatic animals; in the landscape planning of small towns, first considering the development of urbanization, and planning large-scale industrial park, seriously affect the climate conditions in the region, and have the damage to animals' living environment safety.

In the "negative planning" theory, it stresses that in the animal resources, landscape design is required first to ensure the safety of animals living environment. Animals are an important part of the ecological chain. The species diversity and the number of animals could promote the ecological balance.

\section{2) The significance of plant environment safety}

Plants, water, topography, pavement, sculpture itself are the several main elements that constitute the landscape. Plants in landscape design plays the roles of conserving the soil and water without loss, breaking wind and fixing sands, regulating the climate, beautifying the environment, and improving the local microclimate.

From the point of view of landscape planning and design ideas and methods of the traditional small towns, what are mainly considered for plants are: whether the modeling is beautiful or not, and the modeling can achieve beautiful landscape effect from the plane and elevation; how about the cost; a certain kind of trees are grown on the paths of certain grade are grown; which can be used as street trees, which can be used as the courtyard ornamental trees; the growth status of trees, how many years to achieve the desired design effect and so on. And the little consideration is given to problems of the plant itself living environment safety.

Main factors affecting the safety of the plant environment include: the destruction of the soil, water pollution, frequent extreme weather and air quality decline, and all the problems are caused by human being, for they unlimitedly develop the natural resources and extremely do not respect for nature. And the nature will also give humans a reaction, making human living environment under the threat of one kind or another.

The "negative planning" idea in the aspect of the biological landscape security pattern, proposes that landscape planning and design should first consider the safety pattern of the plant landscape, rather than the landscape effect built by plants. Only this way can guarantee the role of plant landscape in the landscape planning and design of small towns.

\section{The significance of human landscape preservation}

Due to the influence of foreign culture and modern culture, as well as yearning for the landscape design form of large and medium-sized city, landscape planning and design in small towns has lost itself and lost direction, which always considers problems about cultural landscape less or only on the shallow level, thus, causing the landscape planning and design of small towns in our country to appear the situation of "thousand towns with same pattern, hundred cities with same appearance".

\section{1) The significance of the preservation of nature landscape}

Tracing the origin of Chinese landscape design, it is found that its history is very long, roughly three thousand years. What we call today is "landscape art and design", and its actual meaning is similar to the ancient Chinese garden design. The development of Chinese classical garden has roughly experienced four stages: the generation period before Han dynasty; the turning point in Wei, Jin, Southern and Northern dynasties; the heyday in Tang and Song dynasties; the mature period of Ming and Qing dynasties. And in the gardening process of the several stages, it is found that our country is not like western countries which have special landscape design disciplines and landscape designers, and most of our landscape design is made by poets, and painters, and other scholars. Besides, in the landscape design, we pay great attention to the construction of mountain and the management of water, and stress the landscape.

Because today's landscape planning and design of small towns in our country is influenced by developers' interests, government performance, the development of urban modernization, and other various conditions, thus in the landscape planning and design of small towns in our country, problems about the preservation of scenic landscape are ignored. This or that reform and development of mountain and water landscape development, can make it lose the original natural form, and no longer have some ecological adjustment function, which damages our living environment, urban image, and the continuation of the cultural history. Therefore, the preservation of landscape in small town's landscape planning and design should be taken seriously enough. 
2) The significance of the preservation of religious culture landscape

Understanding of the word "religion" in Chinese culture is that there is a founder, with the worship object as "ancestor"; there are a group of followers, with certain rituals as "enlightenment". Religion is a kind of special culture in the development of human history, which affects people's spiritual consciousness and living habits. In Chinese traditional culture, religion is an indispensable component. "Confucianism, Buddhism, Taoism" is China's traditional culture, and our culture has been influenced by Confucianism, Buddhism, and Taoist for a long time. In the history of China's development, no matter which place is, and no matter which dynasties, we should first respect the culture that ancestors left behind. The preservation of religious and cultural landscape should not only be the preservation of religious buildings, but also should carry on the preservation of the atmosphere and culture of religion.

In the modern landscape design of small towns, many religious old buildings will be pulled down, reconstructed, and renovated, and some tourism around religious buildings are made vigorously for business benefit, which seriously have damage to the religious culture. Humans, in the urban construction and landscape planning and design, don't respect their ethnic culture, but blindly pursue Western culture and worship things foreign and fawn on foreign countries, or simply add in landscape sketches of traditional forms in the landscape design, and is excessively retro. These cannot truly reflect the respect and inheritance of our religious culture and traditional culture. If human beings lost their own beliefs, and even were regardless of their ethnic culture, then how to achieve the sustainable development of ecology, environment, culture and society. Therefore, the preservation of religious and cultural landscape is particularly important in the landscape planning and design of small towns.

3) The significance of preservation of historic buildings, streets and sites

The preservation of historical buildings, streets and sites is to allow our culture to be passed down, and allow us to stand in front of historic buildings to feel China' s cultural landscape at different times and in different locations. Historical and cultural landscape endows landscape with vitality. If we don't preserve our historic buildings, streets and sites, then our urban landscape will present a stiff, cold, and lifeless landscape form, which no matter landscape architects or viewers are reluctant to see and living in.

The "negative planning" idea makes a positive guidance for the preservation of the culture of historical architecture, reflects on the state of the present historical and cultural landscape, and reflects on the planning method, and the planning process for the pursuit of the right planning results.

4) The significance of the preservation of vernacular culture landscape

Most of the traditional small towns in our country are in the same national culture system, and they maintain consistent in the aspects of buildings' construction, form and aesthetics. However, in the process of urbanization, because of the different natural environment and cultural environment, each town has formed the different local characteristics, the socalled regional characteristics.

Although our history is the same strain, after all, our country is a multi-nationality country and vast in territory. Under the influence of different geographical environment, climate environment, and customs, the landscape of small towns of all regions also presents different landscape forms:

In the building landscape, the buildings of different regions have theirs own architectural style, such as Northern style, Northwest style, Jiangnan style, Lingnan style, Southwest style, Tibetan style, Mongolian style, Uighur style, and other ecological architectural form;

In the green landscape, different regions, according to different natural conditions, have the most suitable native plants to grow in their own regions, which present plant landscape characteristics in the region;

In the waterscape design, on the basis of the characteristics of the local water system, and terrain characteristics, different planning of water form is made, including the landscape design of the surrounding environment of the drainage.

What is design? The management and construction on the basis of the region's characteristics is called design. If the landscape of all regions is formed with the same pattern, then it cannot be called as "design", but rather "reference model". This just reflects the significance of the preservation of local cultural landscape in the landscape planning and design of small towns.

$\mathrm{Yu}$ Kongjian professor, dean of the Graduate School of Landscape Architecture of Peking University, has proposed the" negative planning" idea, which is advanced, scientific and feasible. It is neither against planning, nor not planning. It has priority in emphasis on the control of un-construction regions. And before the whole landscape planning, it conducts planning and protection of leading elements and decisive elements of the landscape, such as the ecological environment of small towns, biological security pattern, cultural landscape features and so on, so as to realize the health, safety and sustainable development of small towns' landscape planning and design. According to the guidance of the "negative planning" theory, the paper tries to research the "negative planning" theory's significance for landscape planning and design of small towns, in the following three aspects: the significance of the natural ecosystem service function; the significance of biological environment safety; and the significance of cultural landscape preservation.

\section{CONCLUSION}

China is currently in the stage of the rapid development of urbanization, and small towns play a vital role in the construction of urbanization with Chinese characteristics. However, because the history of Chinese small towns' construction is relatively short, and there is no unified planning for the small towns' construction, thus there still exist big issues in the construction, planning, and landscape design of small towns in our country. And the core purpose of this research is: to improve the problems existing in small towns' 
construction in our country and landscape planning. Therefore, this article launches the analysis and discussion in three aspects:

First, of the significance of the "negative planning" idea for the landscape design of small towns, in the following four aspects: the landform service function, the climate service function, the soil service function, and the hydrological service function;

Second, of the significance of the "negative planning" idea for the landscape design of small towns, in the following two aspects: the animal environment safety and the plants environment safety;

Third, of the significance of the "negative planning" idea for the landscape design of small towns, in the following four aspects: the preservation of nature landscape, the preservation of religious culture landscape, the preservation of historic buildings, streets and sites, and the preservation of vernacular culture landscape.

Based on the above discussion, the author summarizes the following conclusion:

The above three aspects are mutually integrated, interrelated and influenced each other. And the more comprehensive and deep elaboration, analysis, and demonstration of "negative planning" this new idea and approach, have great significance for the landscape design of small towns in our country.

\section{NOTES}

[1] "Natural Ecosystem", http://baike.baidu.com/view/2864098.htm .

${ }^{[2]}$ World Sci-Tech $R \& D$, Volume 22, Issue 5, Page 45, 2000.

\section{REFERENCES}

[1] Yu Kongjian, et al. The Approach of "Negative Planning” [M]. Beijing: China Building Industry Press, 2011.

[2] Hou Wei, Xu Suning. The "Negative Planning" Thinking of Strategic Environmental Assessment of Overall Urban Planning [J]. Journal of Harbin Industrial University (Social Science Edition), 2009 (4) : 18 - 23.

[3] Luo Zhongzhao, Shang Zhendong, Zhangbo, et al. The Landscape Design of Small Towns [M]. Beijing: Mechanical Industry Press, 2011.

[4] Lu Ning, Lu Lu et al. Modern Urban Landscape Design Problems and Countermeasures [J]. Journal of Architectural Science and Engineering, 2006 (4) : 90-94.

[5] (US) John · O Symonds, Barry · W - Stark. Zhuqiang et al. Landscape Design (fourth edition) [M]. Beijing: China Building Industry Press, 2009.

[6] Wang Yuncai, Liu Binyi. The Discussion of China's Rural Landscape and Rural Landscape Planning [J]. Chinese Garden, 2003 (1) : 55-58.

[7] The World Science and Technology Research and Development [J], Volume 22, Issue 5, Page 45, 2000. 